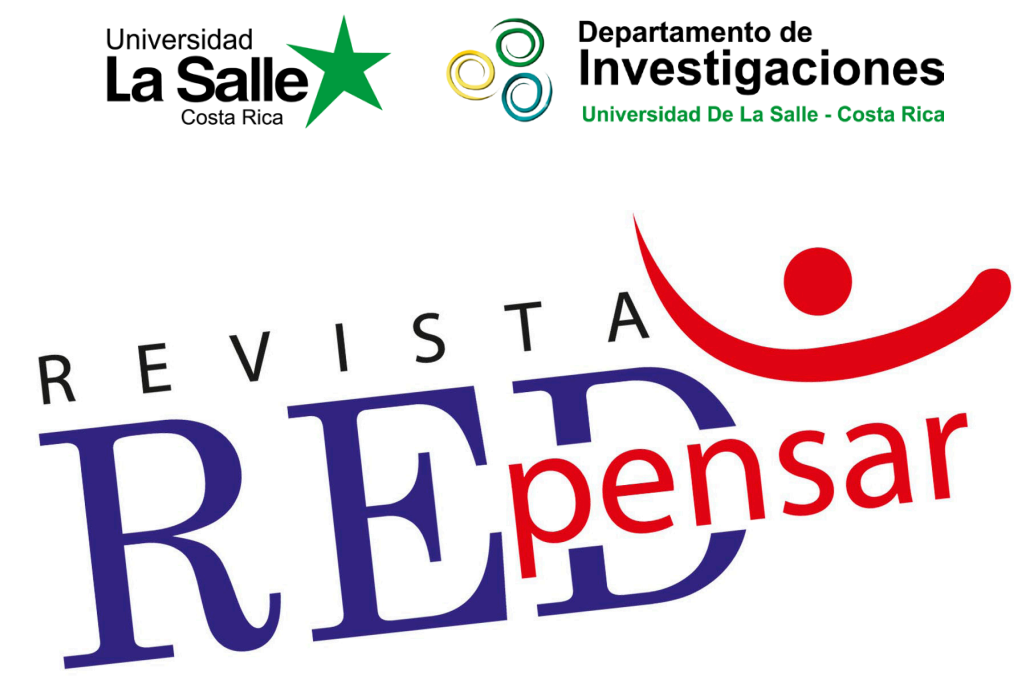

\title{
La hibridez en los orígenes del cristianismo
}

Hybridity on the Origins of Christianity

Hañel José Zúniga Valerio

Revista REDpensar, volumen 8, número 1, Enero-Junio 2019 ISSNe: 2215-5384

Lanzando la RED 3 Recibido: 04 de marzo de 2019 Aceptado: 06 de mayo de 2019

DOI: 10.31906/redpensar.v8.i1.181

\section{(ㅇ)(1)(2)}

Universidad De La Salle Costa Rica 


\section{La hibridez en los orígenes del cristianismo Hybridity on the Origins of Christianity}

\section{Resumen}

Los estudios recientes sobre los orígenes del cristianismo han asumido la interdisciplinariedad como punto fuerte. En particular, el uso de las ciencias sociales aporta al exégeta las herramientas para reconstruir, de manera fragmentaria, los mundos mentales de los protagonistas de los escritos antiguos, canónicos y extra-canónicos. El estudio de la noción de "hibridez" provee una clave metodológica para comprender la interculturalidad plasmada en los textos de los primeros escritores cristianos y aleja al lector de pretensiones anacrónicas que proyectan conceptos como "ortodoxia" u "herejía" en contextos donde la llamada "doctrina cristiana" está en vías de formación.

Palabras Clave: ORÍGENES DEL CRISTIANISMO, CRISTIANISMO PRIMITIVO, NUEVO TESTAMENTO, ORTODOXIA, HETERODOXIA, DOCTRINA, HIBRIDEZ.

\section{Abstract}

Recent studies regarding the origins of Christianism have assumed interdisciplinarity as a strong point. Particularly, the use of social sciences gives the exegete the needed tools to reconstruct, in a partial way, the "mental worlds" of the ancient writing's protagonists, canonical and extra-canonical. The research of "hybridity" as a notion provides a methodological key to understand interculturality which is shown in the first Christian's texts and dissociates the reader of anachronical pretensions which may project concepts such as "orthodoxy" or "heresy" in contexts where the so called "Christian Doctrine" is on its way to be formed.

Keywords: ORIGINS OF CHRISTIANITY, PRIMITIVE CHRISTIANITY, NEW TESTAMENT, ORTHODOXY, HETERODOXY, DOCTRINE, HIBRIDITY.

1. Costarricense. Egresado de la Maestría en Ciencias Bíblicas, Universidad Bíblica Latinoamericana. Licenciado en Ciencias de la Educación, Universidad Católica de Costa Rica. Bachiller de Ciencias Teológicas, Universidad Católica de Costa Rica. Profesor de Nuevo Testamento y Director de la Escuela de Ciencias Bíblicas, en la Universidad Bíblica Latinoamericana, San José, Costa Rica. Correo electrónico: b.zuniga@ubl.ac.cr 


\section{Introducción}

Re-imaginar los orígenes de un movimiento es una manera de buscar la identidad de dicho movimiento. Preguntarse por los inicios plantea dos movimientos: uno hacia el "ayer" y otro hacia el "hoy". Quien cuestiona sus orígenes se dirige al pasado para recuperar, con todos los límites que la memoria y la transmisión de esta implican, fragmentos de su esencia. Pero también, quien se ha empeñado en esta tarea lo hace porque algo en el presente lo obliga a mirar atrás. De esta forma, ese doble movimiento nos ubica en el aquí y ahora de nuestra realidad para replantearla, transformarla, reformarla. Ninguna aproximación histórica es neutral y menos aun cuando hablamos del cristianismo.

El presente estudio está motivado por cuestionamientos más bien prácticos. Buscar los inicios de un movimiento que se convirtió en la religión institucional con mayor difusión en el mundo occidental tiene como trasfondo hacerle preguntas a dicha religión institucional. Parecen preguntas ingenuas, pero no lo son. Están cargadas de un fuerte sentido crítico: ¿está Jesús en los orígenes de esto que llamamos "cristianismo"? (esto nos refiere al contexto y al mundo del personaje histórico Jesús de Nazaret), ¿pensó Jesús lo que vemos hoy? (esto nos lanza a la reflexión eclesiológica), lo que hoy llamamos "dogma" o "doctrina”, ¿fue pensado tal como es enseñado hoy? (esto cuestiona la teología sistemática) ¿Qué tanto las prácticas litúrgicas y los criterios morales de las iglesias responden a la vivencia de Jesús y sus primeros seguidores? (esto nos lanza al mundo de la teología práctica).

Hemos hecho esta salvedad porque no nos mueve solamente el afán historiográfico, sino también las preocupaciones eclesiológicas. No nos limitaremos a los resultados que las ciencias sociales y la arqueología nos arrojen, sino que plantearemos preguntas al hoy de la "iglesia" precisamente porque son las comunidades eclesiales las que se dicen depositarias del mensaje evangélico. Pero, ¿cómo lo han recibido? ¿cómo lo interpretan? Siendo esta una aproximación creyente, no significa que el punto de partida tiene un presupuesto determinado que cierre otras opciones. El punto de partida es, en realidad, el marco de la historia y no tenemos un punto de llegada. Sólo un criterio hipotético está tras nuestra reflexión: el cristianismo es, más bien, los cristianismos. Y esto no es una novedad, sino que responde al ADN del plural movimiento cristiano.

Los primeros siglos del cristianismo presuponen una diversidad inimaginable, inclusive para los cientos de denominaciones cristianas hoy. Las discrepancias que encontramos hoy a nivel doctrinal y práctico son, incluso, más homogéneas que las tendencias de los cristianismos en el siglo II. Cuando algunos dirigentes asentados en grandes urbes intentaron controlar esa diversidad, se inició un proceso que yo llamo de "exchange" o "intercambio" cultural. Un intercambio que implicaba modos de vida, creencias, formas culturales y escritos. Algunas iglesias se apuntaron en este proceso dialógico, cedieron en unas cosas, se cerraron en otras. Negociaron de una u otra forma y conformaron así acuerdos comunes que se reflejan en el canon del Nuevo Testamento: un corpus de veintisiete libros con cristologías, acentos teológicos y étnicos diversos. No obstante, hubo otros grupos que no sobrevivieron esta dinámica. Sea porque se separaron por decisión propia, se mantuvieran al margen o porque fueron atacados por líderes eclesiales, muchos cristianismos fueron olvidados y apenas queda su eco en distintos escritos.

Si el Nuevo Testamento es producto de esta "negociación" podemos encontrar en él evidencias del conflicto con quienes no negociaron. Desde la década de los 50, las fricciones entre las tendencias paulinas y judeocristianas quedan explicitadas porque unos predican "otro evangelio" y se excluyen mutuamente con maldiciones (Ga 1,6-10). Los mismos evangelios sinópticos muestran que hay "falsos profetas" que vienen al grupo "con disfraces de ovejas" siendo lobos. A esos "Jesús" les dirá: "Jamás os conocí! ¡Apartaos de mí, malhechores!” (Mt 7,15.23). El evangelio de Juan y, sobre todo 1 Jn, muestran la secesión de un grupo que ahora son "anticristos" y que "salieron de entre nosotros" (1 Jn 2,18-19). Son llamados "falsos profetas" que niegan elementos de la fe que consideraban "establecidos" (2 Pd 3,3-7). Solo estas escazas citas evidencian la reflexión emic vs. la perspectiva amplia o etic (Bermejo, 2018, p.93), pues las comunidades destinatarias piensan hacia adentro y no de forma extrínseca. La imagen que se construyen de Jesús y de la iglesia es diversa, pero tienen grandes puntos de coincidencia que reflejan el interés por la edificación interna del grupo. 


\section{Un cristianismo, una iglesia: la ficción ortodoxa}

Pues bien, estas políticas de exclusión-inclusión continuaron ya entrado el siglo II y III y se consolidaron en el siglo IV cuando las estrategias del Imperio Romano buscaban unificar "un cristianismo" en medio de un mundo romano diverso a nivel religioso. Constantino y Teodosio olfatearon los procesos de hibridez al ver que las estrategias "ortodoxas" perduraban (Aguirre, 2015, p. 168). Fue Irénée de Lyon (ca. 130-202) que propuso el modelo adoptado como clave para explicar la diversidad del cristianismo: siempre hubo una fe ortodoxa verdadera y la diversidad cristiana refleja movimientos heréticos inspirados por el demonio.

Por una verosimilitud elaborada de modo fraudulento, seducen la mente de los ignorantes y las esclavizan, falseando las palabras del Señor y haciendo malas interpretaciones de lo que ha sido bien expresado. Así causan la ruina de un gran número. Los desvían, con el pretexto de la "gnosis", de Aquel que ha constituido y ordenado el universo: como si ellos pudiesen mostrar algo más elevado y más grande que el Dios que hizo el cielo, la tierra y todo cuanto contienen. De forma engañosa, por el arte del discurso, atraen ante todo a los simples con la manía de investigar; pero luego, sin preocuparse más por lo verosímil, pierde a estos desgraciados, inculcando pensamientos impíos y blasfemos sobre su Creador, a quienes son incapaces de discernir lo falso de lo verdadero (de Lyon, 2001, préface $1^{2}$ ). [Traducción propia del autor al español]

El siguiente texto de Tertuliano (ca. 160-220) nos dejará subrayada la idea de que la ortodoxia precede, temporal y lógicamente, a la herejía:

Nuestra doctrina no es posterior, al contrario, es anterior a todas. Y esto será la prueba de la verdad, que, en todas partes, ocupa el primer puesto [...] Esta es la enseñanza, no digo ya aquella de la que han nacido, pero no son de ella desde que se han hecho contrarias a ella. Hasta del hueso de la oliva, suave, grasa y necesaria, nace el áspero acebuche; hasta de la simiente del higo, tan delicioso y dulce, brota el vano y estéril cabrahígo. Así también las herejías [proceden] de nuestro tronco, pero no son de nuestra familia; [han nacido] de la semilla de la verdad, pero [se han hecho] silvestres por la mentira. (Tertuliano, 2001, pp.35-38).

Esta argumentación se mantuvo y conformó la explicación natural a la diversidad existente en el movimiento cristiano hasta el momento en que Constantino ( $c a$. 272-337) dio un enorme impulso reconociendo la legitimidad de su culto. Eusebio de Cesarea (ca. 263-339) recalca el papel "corruptor" de los herejes en la iglesia antigua:

Por entonces, los herejes seguían con no menor empeño corrompiendo, como cizaña, la limpia simiente de la enseñanza apostólica, y los pastores de las iglesias de todo lugar los ahuyentaban de entre las ovejas de Cristo como a bestias salvajes y los rechazaban, ora mediante las advertencias y exhortaciones dirigidas a los hermanos, ora poniéndoles en evidencia con preguntas y refutaciones orales, cara a cara, y también corrigiendo sus opiniones con argumentos bien precisos por medio de tratados escritos. (de Cesarea, 2008, p.24)

Muchas de las tradiciones eclesiales que conocemos mantienen esta misma idea, con variables más o menos perceptibles, pero finalmente considerando que existió un núcleo genérico de creencias de las cuales otros grupos discrepaban y se diferenciaban. Pero dicho modelo fue cuestionado.

2. "Par une vraisemblance frauduleusement agencée, ils séduisent l'esprit des ignorants et les réduisent à leur merci, falsifiant, les paroles du Seigneur et se faisant les mauvais interprètes de ce qui a été bien exprimé. Ils causent ainsi la ruine d'un grand nombre, en les détournant, sous prétexte de 'gnose', de Celui qui a constitué et ordonné cet univers : comme s'ils pouvaient montrer quelque chose de plus élevé et de plus grand que le Dieu qui a fait le ciel, la terre et tout ce qu'ils renferment. De façon spécieuse, par l'art des discours, ils attirent d'abord les simples à la manie des recherches ; après quoi, sans plus se soucier de vraisemblance ils perdent ces malheureux, en inculquant des pensées blasphématoires et impies à l'endroit de leur Créateur à des gens incapables de discerner le faux du vrai” Irénée de Lyon, Contre les bérésies, SC 264, p. 18-21. Para todo lo que siga emplearemos el texto crítico de Sources Chrétiennes (263-264, 293-294, 210-211, 100, 152-153) traduciendo directamente del francés en comparación con el texto latino provisto.

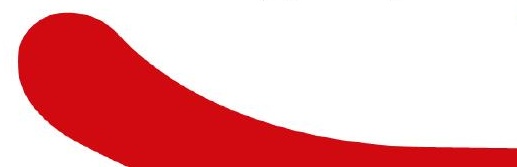




\section{Walter Bauer y su Recbtgläubigkeit und Ketzerei im ältesten Christentum (1934)}

En 1934, el teólogo alemán Walter Bauer (1877-1960) publicó una de esas obras que, decimos en el mundo académico, marcan una época: Ortodoxia y herejía en el cristianismo primitivo ${ }^{3}$. En un detenido análisis de distintas zonas del mundo antiguo, Bauer sostuvo que las formas del cristianismo, que posteriormente fueron consideradas heréticas, precedieron en el tiempo a las que se considerarían ortodoxas en algunas regiones como Egipto y Mesopotamia. No siempre la ortodoxia precedió a la herejía ni tampoco fue mayoritaria.

Triunfaron la forma de fe y el modo de vida cristianos empleados por la organización más fuerte, los más unitarios y los mejor adaptados en gran número, aunque, como yo lo pienso, los cristianos ortodoxos y antiheréticos convencidos han sido menos numerosos que el conjunto de los "heréticos", siendo así por mucho tiempo todavía después del final del periodo postapostólico. (Bauer, 2009, p. 257)

A pesar de que muchas de las tesis de Bauer, referentes a juicios históricos, fueron desmentidas (Hartog, $2015)^{5}$, sus intuiciones fundamentales constituyeron un giro fundamental en los estudios sobre los orígenes del cristianismo. Una de las perspectivas de análisis más aceptada hoy se desprende de la obra de Bauer, a saber, que:

[...] nunca existió un solo cristianismo; antes bien, distintos grupos cristianos compitieron entre sí en los primeros años. Al final, una forma de cristianismo terminó por dominar en varias zonas del antiguo mundo mediterráneo, pero solo tras un periodo de lucha. (Brakke, 2010, p. 23)

Esta forma de ver el desarrollo del cristianismo de los orígenes puede ser ejemplificada por dos metáforas: la del caballo de carreras y la de la guerra. Para Rousseau (1985), el "caballo" que finalmente ganará la carrera está representado por la "proto-ortodoxia" de Ireneo, Justino, Clemente, etc. Asimismo, para Ehrman (2004) los "cristianismos perdidos" lo son porque, en primer lugar, la mayoría de sus escritos fueron destruidos y, en segundo lugar, porque realmente "perdieron" la "batalla" frente al "arsenal" de la "proto-ortodoxia": sucesión apostólica, la regula fidei, un canon de Escrituras más o menos delimitado, etc. En ambos casos, la idea fundamental es la de competencia y lucha entre diversos grupos cristianos. A pesar del avance que este modelo explicativo presenta con respecto al de Ireneo, la exegesis contemporánea busca planteamientos más dinámicos y menos reductivos.

\footnotetext{
3. Para las referencias emplearemos la edición francesa : Orthodoxie et hérésie aux débuts du christianisme (2009).

4. "Ont triomphé la forme de foi et le mode de vie chrétiens portés par l'organisation la plus forte, les plus unitaires et les mieux adaptés au grand nombre, bien que, comme je le pense, les chrétiens orthodoxes et 'antihérétiques', et ce longtemps encore après la fin de la période postapostolique".

5. Vale la pena mencionar el reciente estudio divulgativo de Catherine Nixey sobre la lucha impuesta del "mundo cristiano" en los albores de la Edad Media. No obstante, sus imprecisiones históricas y olvidos que, sinceramente espero, no sean intencionales o presupuestados (Nixey, 2018).
} 
No hay un único factor, como el de una "lucha", que pueda explicar el olvido sistemático de grupos cristianos alternativos. No es posible hacer una distinción esquematizada entre quienes son "ortodoxos" y quienes son "heterodoxos" porque los grupos son más "porosos". Es decir, autores considerados "normativos" asumen elementos del gnosticismo, marcionismo, montanismo, etc., como los "herejes" se apropian de elementos de la tradición posteriormente canonizada ${ }^{6}$. No existió una única y definida "proto-ortodoxia" sino una multiplicidad interna en sí misma. La supuesta "marca" de identidad de los caballos no es tan clara: las personas y las ideas están sujetas al constante devenir, a diferencia de los combatientes o los competidores de una batalla.

\section{Una nueva perspectiva: dinamicidad y formación de la identidad}

Precisamente, para dejar de centrarnos en grupos aislados buscando, infructuosamente, sus delimitaciones, nos proponemos adentrarnos en una perspectiva que busque nuevos caminos, que replantee nuestra metodología. Es decir, en las estrategias por medio de las cuales grupos e individuos tratan de definirse a sí mismos sin dar por sentado definiciones "nítidas". En el caso de los diversos cristianismos, cómo estos compusieron textos, construyeron una memoria compartida y promovieron mecanismos selectivos de asimilación, inventaron tradiciones, desarrollaron sus rituales y crearon sus formas doctrinales, definieron a "los otros", entre otros factores (King, 2008, 71-73). Podríamos condensar estos mecanismos en tres temas fundamentales:

\section{a. Hibridez}

Caracteriza la mezcla, combinación e injerto de elementos culturales dispares. Hasta aquí podría parecerse al viejo concepto despectivo de "sincretismo", sin embargo, la hibridez denota las relaciones culturales inevitables de los distintos grupos sociales, particularmente, en ambientes de dominación colonial donde dominante y subalterno se relacionan e intercambian valores creativamente. Esta realidad explica cómo las culturas dominadas pueden subsistir.

Los clásicos conceptos "cosmovisión" y "sistema simbólico", deudores de las obras de Berger (1969) y Geertz (2003), han ayudado a identificar los sistemas de valores en los sistemas religiosos, no obstante, también han perjudicado al crear interpretaciones poco dinámicas suponiendo armonía y holismo donde generalmente hay conflicto y reinterpretaciones continuas. Un ejemplo claro es el caso de Justino Mártir, que crea y defiende una noción de "ortodoxia" incipiente y distinta de lo que luego entenderemos por tal: siendo un autor enteramente heredero de las culturas griega y romana, se enfrenta a ellas planteando que la verdad universal (el logos Jesucristo) ya estaba allí, en Sócrates, Platón y Aristóteles, sin ellos saberlo: "y es que los escritores todos sólo oscuramente pudieron ver la realidad gracias a la semilla del Verbo implantada en ellos" (Apol. II, 13,5) . Él y otros compartían una misma cultura que decían rechazar. Esto se llama "hibridez".

\footnotetext{
6. 'La iglesia y la investigación crítica describen como 'proto-ortodoxos' a personas y grupos que iniciaron trayectorias que perfectamente pudieron no haber culminado en la ortodoxia nicena y que se sorprenderían de haberse encontrado incluidas en una misma categoría. Clemente e Ireneo podrían coincidir en que los gnósticos estaban equivocados respecto a la naturaleza del Dios del Génesis, pero Clemente se mostraba escéptico ante los obispos, y afirmaba que Cristo enseñó una gnōsis secreta a sus apóstoles, quienes a su vez a transmitieron a maestros bien formados como él. Valentín hubiera estado de acuerdo con esta idea, mientras que Ireneo no. Pero el mismo Ireneo se parecía, más de lo que era capaz de admitir, a los gnósticos que odiaba. Condenó a estos por crear una compleja serie de divinidades y mundos celestiales y por rastrear la salvación de forma genealógica hasta los hijos de Adán, aunque él también describió una serie de siete cielos gobernados por distintas potestades, e igualmente rastreó las potestades de Dios en una genealogía desde los hijos de Noé. Por consiguiente, no había un solo caballo proto-ortodoxo en la carrera ni un solo ejército proto-ortodoxo en la guerra: la proto-ortodoxia misma era sumamente diversa y, en muchos sentidos, poco ortodoxa" (Brakke, 2010, p. 28-29) [El subrayado es del autor del artículo]

7. Para lo subsecuente, nos centraremos en el resumen de Brakke (2010, p. 30-41).

8. "Les écrivains ont pu voir indistinctement la vérité grâce à la semence du Verbe qui a été déposée en eux".
}

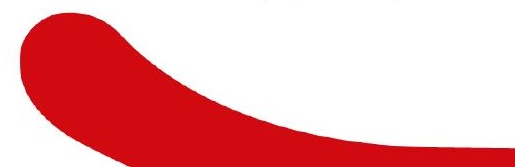


Las ambigüedades y las contradicciones son parte de esta hibridez. Los movimientos sociales y religiosos, hasta la fecha, coexisten con ideas plurales, diversas y hasta antitéticas. Los cristianismos actuales son tan divergentes como tan coincidentes y esto solo refleja una condición humana de alteridad e integración.

\section{b. Retórica}

El uso de las estrategias discursivas sirve para imaginar al "otro". Dicho de otro modo, tanto autores eclesiásticos como paganos emplean estrategias retóricas de diferenciación. La clasificación "ortodoxia" y "herejía" son, asimismo, términos retóricos para distinguirse de otros. Le Boulluec (1985) cuestiona la concepción estática del mismo Bauer, para quien era perfectamente distinguible en ideas o grupos la "ortodoxia". Para Le Boulluec, en cambio, "ortodoxia" y "herejía" son una "representación" que remiten a un discurso diferenciador para establecer límites y crear identidad. Todos los autores antiguos crean sus propias nociones que clasifican a otros y marcan límites.

\section{c. Etnicidad}

Este lenguaje de ciudadanía jugó un papel destacado en la retórica de auto-diferenciación. Los cristianos se denominaron a sí mismos "tercera raza" (además de "judíos" y "gentiles" o "griegos" y "bárbaros") y de esta manera se concibieron como una "nueva nación", un "nuevo Israel" en otros círculos, la "simiente de set" (gnósticos setianos), etc. Es el cristianismo un "tercer género" que asume la pluralidad en un proceso de mestizaje e hibridación (Rivas, 2003, pp.51-53). Este tipo de distinción lo encontramos ya en la teología del judaísmo del Segundo Templo. La diferencia radica en que, los estudiosos modernos entienden que la identidad cristiana no es algo dado, sino elaborado, desafiado y luego legitimado (Buell, 2005).

Todas estas categorías de análisis cuestionan las visiones estáticas de "el cristianismo" enfrentado a su entorno y nos deja entrever que, en realidad, son "los cristianismos" los que se nos hacen presentes. Que cada uno de estos cristianismos elaboraron sus propios discursos y prácticas pero que compartían muy a menudo, a pesar de que dijeran lo contrario, doctrinas y rituales, así como formas de vida que nos hace considerarlos "hijos de su tiempo": judíos, griegos, romanos, que no dejaron de serlo, sino que se asimilaron entre sí.

\section{Concluyendo: los cristianismos olvidados}

Si abordamos nuestro estudio comprensivo de los "cristianismos olvidados" desde esta perspectiva debemos retarnos a no asumir criterios dogmáticos en la creación historiográfica. La misma academia ha creado sus dogmas y debemos estar dispuestos a cuestionarlos. No existen realidades estáticas sino dinámicas y los cristianismos primitivos creaban y transformaban sin cesar sus propias identidades. También debemos reconocer que las fronteras entre los grupos son "porosas" es decir, existieron, pero más flexibles de lo que sus mismos protagonistas nos quieren hacer ver. Con el paso de los siglos, dicha flexibilidad se fue haciendo más rígida en algunos aspectos (doctrinales, morales) pero siempre en proceso de una construcción activa. Es menester tener en cuenta que los cristianismos fueron eso "cristianismos" puesto que compartían elementos comunes de la fe en Jesús, con distintas facetas cada uno de ellos, con distintas respuestas, pero refiriéndose a quien creyeron fue la manifestación más plena de Dios, del Uno, de YHWH.

No podemos, asimismo, obviar que necesitamos crear categorías de análisis. Tanto hemos cuestionado los límites que el lector podría pensar que está pisando terrenos sinuosos, pero no es así. Consideramos que la creación de categorías es necesaria para la comprensión moderna de la pluralidad cristiana, pero es precisamente eso, una creación nuestra dependiente de diversas realidades antiguas. Debemos buscar, de la forma más intelectualmente honesta, una clasificación para comprender el diálogo entre grupos diversos que no encasille, sino que permita distinguir en medio de la pluralidad, es decir, que permita reconocer los puntos de contacto, así como las contradicciones. Es así como podemos diferenciar grupos, tradiciones y movimientos que se construyen por la hibridez, el discurso y la etnicidad. Y todos ellos conforman una magnitud identificable como "los cristianismos". 
Algunos de esos grupos y tradiciones fueron "olvidados" involuntariamente, otros adrede. Algunos cristianismos no supieron adaptarse y por sus condiciones internas se extinguieron. Otros sucumbieron a los ataques de los cristianismos mejor adaptados. Pero todos cuentan una historia que puede ser, fragmentariamente, recuperada. No es una carrera de caballos ni una batalla la que los hizo perder, sino más bien una dialéctica que combina esos factores y otros la que los hizo quedar en el olvido de nosotros, lectores modernos que recibimos el influjo de cristianismos "recordados". No olvidemos que esos cristianismos recordados son, a su vez, un producto de la hibridez con los cristianismos olvidados. Tanto hay de judeocristianos, helenistas, gnósticos y marcionitas en nosotros que, rápidamente, dejamos de captarlo porque los ingredientes se pierden en un mismo sabor que creemos único. Pero no es así, somos producto de un encuentro cultural.

\section{Referencias Bibliográficas}

Aguirre, R. (2015). La memoria de Jesús y los cristianismos de los orígenes. Estella, España: Verbo Divino.

Bauer, W. (2009). Orthodoxie et hérésie aux débuts du christianisme. Paris, France: Du Cerf.

Berger, P. (1969). El dosel sagrado. Elementos para una sociología de la religión. Buenos Aires, Argentina: Amorrortu.

Bermejo, F. (2018). La invención de Jesús de Nazaret. Historia, ficción, historiografía. Madrid, España: Siglo XXI.

Brakke, D. (2010). Los gnósticos. Mito, ritualy diversidad en el cristianismo primitivo. Salamanca, España: Sígueme.

Buell, D. (2005). Why This New Race: Ethnic Reasoning in Early Christianity. New York, United States: Columbia University Press.

de Cesarea. E. (2008). Historia eclesiástica. Texto bilingüe. Madrid, España: Biblioteca de Autores Cristianos.

De Lyon, I. (2001). Contre les hérésies. France: Sagesses Chretiennes.

Ehrman, B. (2004). Cristianismos perdidos. Los credos proscritos del Nuevo Testamento. Barcelona, España: Crítica.

Geertz, C. (2003). La interpretación de las culturas. Barcelona, España: Gedisa.

Hartog, P. (2015). Orthodoxy and Heresy in Early Christian Contexts. Reconsidering the Bauer Thesis. Cambridge, United States: James Clarke \& Co.

King, K. (2008). “Which Early Christianity?”. En A. Harvey - D. G. Hunter (Eds.), The Oxford Handbook of Early Christian Studies (pp.71-73). Oxford, England: Oxford University Press.

Le Boulluec, A. (1985). La notion d’hérésie dans la littérature grecque (IIe-IIIe siècles). Paris, France : Études Augustiniens.

Nixey, C. (2018). La edad de la penumbra. Cómo el cristianismo destruyó el mundo clásico. Madrid, España: Taurus.

Rivas, F. (2003). El cristianismo como tercer género: mestizaje cultural. Reseña bíblica: Revista trimestral de la Asociación Bíblica Española, (40), 49-56.

Rousseau, P. (1985). Pachomius: The Making of a Community in Fourth-century Egypt. Berkeley, United States: University of California Press.

Tertuliano. (2001). "Prescripciones” contra todas las herejías. Madrid, España: Ciudad Nueva. 